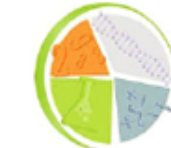 \\ Revista Educar Mais}

EDITORIAL

\title{
Por que o mais certo é o incerto?
}

\author{
Prof. Dr. Renan Antônio da Silva ${ }^{1}$
}

Humanos sempre flertaram com a noção de "verdade" e até hoje a ciência ainda se refere a ela como seu padrão de realismo. Religiões, nem se fala. Políticos igualmente. Em seu livro provocativo sobre a "mente justiceira" (ou reta, endireitadora) (righteous mind), Haidt (2012) discute a obsessão humana pela verdade, a ponto de acharmos que temos o direito de endireitar a cabeça dos outros. Os colonizadores assim procederam: "evangelizaram" os indígenas a ferro e fogo, como a Igreja Católica já fizera, instituindo a Inquisição ou assumindo as Cruzadas. "Donos da verdade" é fenômeno comum em sociedades humanas, como são moralistas (gente que prega a moral que não cumpre), políticos que prometem o que não podem, santos-do-pau-oco. Em religiões, sobretudo cristãs monoteístas, a verdade é referência necessária e fundante para cada religião, por conta da pretensão de ser unicamente verdadeira, tão unicamente verdadeira que outras só podem ser fraudulentas e merecem a condenação peremptória. Já chegamos a tempos de ecumenismo - em universidades alemães teologia protestante e católica são cursos plenos paritários e em geral fraternais - mas, na prática, não funciona. Ecumenismo significaria que, sendo as religiões igualmente "verdadeiras", não faria diferença estar numa ou noutra. Mas não vale isso. Ecumenismo é para o outro adotar minha religião, se tiver juízo!

Ao final, contudo, precisamos de alguma certeza, porque não é viável/saudável viver de supetão permanente. Mesmo quando dizemos "não acreditar em nada", acreditamos em alguma coisa, por mais indefinida que seja, porque não é possível ficar de mente vazia, nem na ioga. Não reconhecer valor nenhum é gostar de um valor, mesmo tão negativo. Se precisamos de certeza, não é menos decisivo questioná-la, pois nada emburrece mais que certezas, como nada intranquiliza mais que incertezas. Donos da verdade não aprendem, não mudam, não ouvem, não cooperam... Em suma, somos seres ambíguos: dialéticos no sentido de que somos unidades de contrários, ou mesmo contraditórios, tal qual é complicado arrumar o comportamento racional e o emocional no mesmo cérebro (Damasio, 1996; 2018). O modo de validade em sociedade e em contextos evolucionários vivos é "relativo", embora não relativista - as coisas valem, mas valem relativamente, inclusive no campo da ética (Demo, 2005).

\footnotetext{
${ }^{1}$ Pesquisador Titular no Departamento de Pesquisa do Centro Universitário do Sul de Minas (Unis). Professor Visitante no Programa de Pós - Graduação em Educação (Mestrado e Doutorado) da Universidade Federal do Amazonas - UFAM. Professor e Pesquisador Visitante no Programa de Pós - Graduação em Educação pela Universidade Federal do Pampa (UNIPAMPA). Pesquisador Colaborador Júnior junto ao Programa de Pós Graduação em Direitos Humanos e Cidadania da Universidade de Brasília - UnB. E-mail: r.silva@unesp.br
} 


\section{CERTEZA SÓ TEMOS DA INCERTEZA}

Na luta por erigir algum sentido da vida, junto com melhorar a segurança (Hecht, 2003. Fields, 2011. Rothman \& Sudarsham, 1998), humanos propuseram muitos "métodos" de abordagem. O mais antigo é o religioso. Tomando um cenário bem provável na savana africana há mais de 100 mil anos atrás, num momento de tormenta violenta, regada a raios retumbantes, com água descendo aos jorros e num céu escurecido tenebrosamente, é "natural" que os humanos se sentissem muito pequenos diante de tamanhas forças que pareciam incontroladas e incontroláveis. Nada mais seguro que contar com uma segurança pretensamente absoluta, divina. Este é um caso extremo de impotência, mas é sensação comum da vida que não nos abandona nunca: somos dependentes, uns dos outros, dos outros, e de forças acima de nós. Alguns diriam que religiões são motivadas, pelo menos em parte, pela sensação de impotência humana - quando, tomados pelo desespero existencial, apelamos para um ser maior, com o qual gostaríamos de ou precisaríamos contar (Bellah, 2011). De acordo com o poder desse ser superior - no politeísmo o poder é dividido, mas no monoteísmo é um Deus só, todopoderoso - humanos fabricam a verdade, que no cristianismo e no islamismo são textos sagrados, escritos por humanos sob inspiração direta divina. Socialmente falando, porém, mesmo tendo como referência um livro sagrado, divino, não é viável termos no planeta religião única, porque divergências são absolutamente naturais, sem falar na ambiguidade interpretativa natural ancorada em experiências subjetivas e culturas diversas. Da mesma bíblia não saem apenas religiões diversas, mas igualmente adversas, que podem - hipocritamente pregando o amor - exterminar crentes de outra versão. Podemos então indicar que verdade religiosa também tem dono, porque tendo humanos que interpretar textos sagrados, o fazem de modo diversificado, por conta da experiência subjetiva de cada qual ou de cada grupo. Não somos possuídos pela verdade; possuímo-la, fazendo dela um bordão de supremacia, em geral farsante.

Outro método foi a "sabedoria" (Santos, 2009. Santos \& Meneses, 2009. Watts, 1951. Sternberg, 1990), em geral atribuída aos mais velhos da tribo, ou colhida na saga de cada grupo, armazenando ditos e fórmulas dos antepassados (Haidt, 2006. Hooks, 2009. Kekes, 1995. Assim fomos elaborando modos de lidar com a doença, com a procriação e criação dos filhos, com os poderosos e governos, com a sobrevivência etc. Sábios, porém, tendem a ser donos da verdade, menos quando são como Sócrates (como conta a lenda) que se definia como aventureiro perscrutador dela, não como proprietário. É fato, de todos os modos, que cada grupo humano erige uma visão própria da verdade, daquilo que considera certo, também ético, do que se imagina ser obrigação passar para as novas gerações. Neste ambiente cultural, há posições consideradas verdadeiras que perfazem o lote de experiências e conhecimentos vistos como patrimônio comum a ser preservado. Similar à religião, mitos podem cumprir este papel de verdade existencial. Entretanto, não serve sabedoria como referência absoluta, porque as versões não podem ser. Sábios são até certo ponto "universais", ao refletirem máximas globalizáveis, mas, na prática, são datadas e localizadas. Sabedoria, porém, ganhou enorme upgrading com as novas tecnologias digitais, tal qual assinalou Wales (dono da Wikipédia) com o termo "sabedoria das multidões" (2006). Surowiecki popularizou o termo (2004): muitos são mais inteligentes que poucos, não apenas somativamente, mas exponencialmente (Davies, 2007. Kittur et alii, 2007). Uma plataforma como a Wikipédia pode ter este charme inovador e surpreendente, mesmo também questionada pela academia mais rígida (Giles, 2005. Lih, 2009): a autoria coletiva pode ser mais abrangente e efetiva que a autoria individual. Alude-se, então, a "novas epistemologias" (Demo, 2011) ou à "ciência aberta" (Nielsen, 2012. Cribb \& Sari, 2010), assinalando o valor epistemológico da intersubjetividade crítica autocrítica ancorada na autoridade do argumento, não no argumento de autoridade. O texto na Wikipédia subsiste se tiver argumentação 
intersubjetivamente aceitável, já que, a todo momento, pode ser reeditado ou mesmo apagado. Talvez tenhamos de reconhecer que a "ciência" exercitada na Wikipédia é mais flexível, tolerante (embora nos textos das ciências exatas e naturais a qualidade seja bem similar), mas tem a graça imensa de permitir acesso a multidões de pesquisadores e aprendizes, sendo, por isso, uma das formações mais preciosas em termos de "educação científica" (Prensky, 2008; 2012).

Outro método é o científico da era modernista, prenunciado na Grécia antiga, segundo o qual o procedimento lógico-experimental pode garantir a verdade de um discurso. Sempre manteve a pretensão de substituir a religião e outros "conhecimentos" considerados espúrios ao método, mas não conseguiu e, pior que isso, também assumiu o lugar da religião, em especial quando pretende oferecer "uma teoria final" (Hawking, 2006) ou expurgar, pura e simplesmente, que a vida possa ter sentido (Weinberg, 2020. Kauffman, 2019). É pretensão excessiva elaborar uma "teoria final", porque não há autor final. A "teoria" do Big Bang pode ser pior que o criacionismo, porque postula uma "autoexplosão" (onde não haveria nada, como forjar uma explosão que só pode ser, logicamente, uma autoexplosão?). É bem mais "racional" reconhecer que não temos ideia de como o universo começou, se é que começou... Para citar um exemplo tópico, relativo a um jornalista da ciência, Horgan: em texto de 1997, proclamava o "fim da ciência", como se estivéssemos prestes a completar a descoberta científica do universo todo. Em 2012 saiu a tradução em português de novo texto, totalmente em outra direção, ao reconhecer que a "ciência não consegue replicar, medicar e explicar o cérebro humano". A fantasia de uma teoria final (Gribbin, 1998. Barrow, 1994) em nada difere de uma bíblia sagrada absolutamente verdadeira, que pode ser fundamental para religiões, mas nunca para a ciência. Ciência precisa alinhar-se ao processo evolucionário e admitir que não tem como incorporar qualquer ponto final. Por isso, grosso modo, temos duas mundivisões da ciência: uma, positivista ferrenha, pleiteia ter condição de desvendar o universo via método científico, alcançar a verdade final; outra, mais dialética e aberta, se vê como processo de aproximações sucessivas e interrelacionadas, que se refina intelectual e evolucionariamente, mas não se conclui. Esta segunda visão aparece, com ênfase ostensiva, em Harari, em especial no "Homo sapiens" (2015), onde descreve ciência como conquista eterna aberta - o que falta conhecer é a referência fundamental, sempre muito maior do que o conhecido, mas também em "Homo deus" (2017) e "Lições para o século XXI" (2018). Ecoa proposta como de Firestein (2012) que vincula ciência à ignorância: ciência não acaba com ignorância (seria ignorante se isto pretendesse), mas reduz a abrangência da ignorância, à medida que exige a autoridade do argumento.

Tal distinção, mesmo tão sumária, indicaria modos também divergentes de promover a "educação científica", considerada pilar crucial da escola atual, começando no pré-escolar (Linn \& Eylon, 2011. Slotta \& Linn, 2009): positivistas duros insistem na descoberta da verdade (final); outros apontam que o processo de elaboração científica medra em ambientes críticos autocríticos (socráticos, digamos), onde a fundamentação, devendo ser a mais acurada possível, nunca é final. Na primeira versão, entende-se ciência como substituta da religião; na segunda, como alternativa ancorada em método intersubjetivo de controle que mantém todo discurso científico como "discutível" (Demo, 2011a). Na primeira impera a doutrinação, na segunda a formação aberta (Ramirez, 2013). Ciência não se alinha a nenhum conceito ou prática da "verdade", porque seu empreendimento é de pesquisa aberta e nunca encerrada; rever-se, reinventar-se é ainda mais importante do que possíveis resultados aclamados. As humanidades apresentam menor resistência a ver ciência como produto social também (não só, certamente), por vezes provocativamente, como em posições de Poerksen sobre "certeza da incerteza" (2004) ou de Foerster \& Poerksen que definem "verdade como invenção de um mentiroso" (2008), considerando que só um mentiroso teria pretensão de ser absolutamente verdadeiro. Esta 
linguagem é desabrida demais para as ciências duras, em parte porque ignora os formalismos analíticos do método, mas nos leva a repensar a ligação entre ciência e verdade, como fizeram também algumas alas positivistas, tal qual a popperiana: teorias não são "verificáveis", são construtos tentativos e revisáveis; podem ser apenas "corroboradas", mantendo-se, porém, sempre falsificáveis (Demo, 1995).

Na existência concreta, o que experienciamos é a condição de incerteza, cercada de algumas ilhas menos incertas, seja porque não sabemos o amanhã, embora tenhamos uma certeza, a saber, que vamos morrer; seja porque vamos envelhecendo naturalmente, tornando-nos menos aptos a sobreviver; seja porque tudo que sabemos sempre pode ser revisto, por vezes até invalidado; seja porque verdade sempre tem dono, em geral safado. Mesmo assim, vivemos fabricando certezas, porque é mais cômodo inventar muletas, se não sabemos andar sozinhos. Para muitos, a solução é religiosa: tendo um Deus como muleta, podemos nos acalmar e até mesmo a morte se torna menos dramática.

\section{LIDANDO COM O INCERTO}

A maneira evolucionária para lidar com a incerteza é buscar nela linearizações recorrentes, repetitivas, abordando-a através da padronização; esta maneira evolucionária é corroborada, entre outras démarches, pela ciência que se baseia na formalização linearizada da realidade, entendendo a variação pela invariância. Por alguma "deficiência" de fábrica, nossa mente não entende a dinâmica pela dinâmica, pois entende via seus códigos, gramáticas, sintaxes, infraestruturas. É um reducionismo "normal", que é tanto mais estupefaciente porque algum domínio da infraestrutura é suficiente para manobrar a superestrutura. Um dos primeiros vislumbres dessa condição é postular que a infraestrutura é mais importante, tal qual Marx considerou: para entender a sociedade, sua história e funcionamento, precisamos desvendar sua infraestrutura material que é determinante. $\mathrm{A}$ superestrutura é decorrente. Ou, como dizem muitos economistas da educação, para entender educação cumpre decifrar a economia infraestrutural dela (Caplan, 2018. Brennan \& Magness, 2019. Ioschpe, 2004), sendo outras dimensões superestruturais como pedagogia, didática, filosofia, aprendizagem firulas consequentes. Encontramos aqui uma das ambiguidades mais contundentes da existência humana (March, 2011. Suri \& Bal, 2010): cuidamos de enquadrar certezas em rotinas, para torná-las previsíveis, mas é na rotina que nos afogamos. Precisamos da rotina tanto quanto precisamos dela nos livrar.

A maneira evolucionária de "domesticar" a incerteza foi corroborada por muitos tipos de conhecimento com realce para o científico, cujo método se dedica a rebuscar leis e regularidades formalizáveis, linearizáveis, sequenciais, reduzindo dinâmicas a suas recorrências não dinâmicas. É procedimento ostensivamente reducionista, mas considerado normal até certo ponto; a partir desse ponto difícil de discernir, começa o positivismo. Mais intrigante ainda que o reducionismo epistemológico, é o resultado ontológico: basta para interferir na realidade com êxito verificado, em especial nas tecnologias práticas. Para montar um avião seguro, não precisamos saber tudo sobre a realidade pretensão totalmente impossível - bastando dar conta das recorrências reprodutivas que, por sua vez, parecem dar conta das dinâmicas. Para fazer um carro autoconduzido, não precisamos decifrar a realidade toda que contorna o carro, mas os padrões recorrentes que têm a ver com a condução autônoma, sabendo que os sensores nunca apanham tudo, que a digitalização nunca é completa, que o reconhecimento de objetos não será perfeito. Como, no entanto, nesta dimensão da linearização 
de realidades complexas a máquina é muito superior a nós, é certo que o carro autoconduzido terá muito menos acidentes, não vai cometer infração de trânsito, a não ser por insciência ou mau funcionamento, não vai dirigir provocativa ou perigosamente, vai adaptar-se bem melhor aos engarrafamentos etc.

Importante, então, lembrar: este esforço linearizante não produz certeza; diminui a incerteza, por uma iniciativa de padronização aproximativa que nunca será completa. E aí podemos equilibrar as fronteiras. Enquanto positivistas juram que vale mesmo a infraestrutura invariante, outros valorizam as dinâmicas, porque a realidade, pelo menos na teoria física clássica e quântica, é essencialmente dinâmica. Para essas teorias, se fôssemos instados a revelar o que seria mais importante, seria a dinâmica. Não sabemos explicar por que a mente não trabalha a dinâmica pela dinâmica - talvez precisemos de mais alguns milhões de anos para chegar lá evolucionariamente - parecendo claro que, para lidar com a realidade, precisamos de uma reconstrução mental reducionista. Assim, não lidamos com a realidade como tal - que não sabemos o que é - mas com um construto mental dela, tal qual acontece numa tabela ou num gráfico: os números ou a figura não são "a" realidade, mas uma reconstrução mental dela, reduzida, padronizada, linearizada. Quanta realidade está por trás dessa montagem mental é uma pergunta grande com resposta pequena, sempre insuficiente. Provavelmente há mais realidade numa abordagem científica, por conta do método, mesmo sendo tão seletivo e enviesado, do que em sensos comuns, religiões, mitos etc. Em nenhuma abordagem, nem na científica, temos a chance de desvendar a realidade por inteiro, porque esta é muito mais complexa e enorme do que nossa capacidade de captação. Nossa capacidade de captação, que também tem dimensões formidáveis, como a habilidade hermenêutica de comunicação, sempre é tentativa, aproximativa, melhorando com a evolução e com a experiência, mas não se conclui, tais quais nós mesmos que não seremos seres concluídos; estaremos - se evolução é teorização minimamente realista - sempre a caminho.

Nossos sentidos são, num lado, uma maravilha da natureza (olhos, ouvidos, tato, olfato, gosto), e, noutro, equipamentos em formação, tanto que outros animais, em geral, possuem sentidos bem mais aguçados (Brynie, 2009). Uma águia - assim consta - vê um rato na grama a 2 mil metros de altura; para nós seria inviável. O morcego guia-se pelo sonar, uma habilidade incrível que não temos. Alguns animais ouvem a grandes distâncias, como elefantes, inalcançáveis para nós. Cães tem olfato apuradíssimo, podendo ser detetives bem mais eficientes que nós. Somos facilmente ultrapassados por outros animais, menos num item: como aponta Herculano-Houser (2018), a "vantagem humana" está no formato cerebral, bem mais "evoluído" que em outros animais, embora disso não decorra nenhuma "superioridade". Assim, nossos sentidos captam a realidade como podem, evolucionária e culturalmente, nunca por inteiro, pois nenhum olho pode ver tudo, por mais que possa indefinidamente aperfeiçoar-se. Neste contexto, aparece uma congruência notável: lidamos com incerteza padronizando-a, não a eliminando; o resultado tem sempre graus variáveis de incerteza. $\mathrm{E}$ a estatística abraça esta ideia, em especial a versão bayesiana (McGrayne, 2011): trabalhamos normalmente com probabilidades. No exemplo do "comportamento", humanos comportam-se "regularmente"; não é assim que todo dia se inventa novo comportamento; mas, ao permanecer idêntico, vai mudando, tal qual numa foto da infância: somos os mesmos, bem diferentes agora. Por mais que o comportamento seja rotineiro, pode mudar, porque, para permanecer o mesmo, há que mudar. Permanecer o mesmo sem mudar é deformação.

Alguns, então, declamam as belezas da incerteza, por facultar atividades como "pensar, pesquisar e criar" (Solomon, 2000); caos pode combinar-se com chances de se reinventar (Collins \& Hansen, 
2011); agarrar-se apenas a fatos, lógica, razões é a rota da mediocridade - é importante rebelar-se (Biederman et alii, 2018); questões são as respostas, porque nunca esgotam as dúvidas que nos fazem nos reinventar (Gregersen, 2018). A mente é basicamente normativa (gosta de recorrências), mas é criativa quando explode esta rotina (Haack, 2019). Não falta gente que gostaria de acabar com as incertezas, em geral em nome da ciência: Lents reage aos "erros humanos", inclusive fisiológicos (ossos mal postos ou genes quebrados) (2018); Peral \& Mackenzie declamam a capacidade de perguntar, mas para reeditar a "nova ciência da causa e efeito" (2018), retomando um positivismo pretérito; Buonomano descreve os "bugs do cérebro" e como tais falhas moldam nossas vidas (2011). Não aprecia um dos lados mais impressionantes do cérebro: sua plasticidade incrível (Costandi, 2016. Ramachandran, 2012. Doidge, 2007. Dehaene, 2009), uma máquina aberta que se renova em sua própria aplicação; vai perdendo a flexibilidade com o envelhecimento, mas mantém-se plástica até ao fim, como condição interna.

Em termos histórico-evolucionários, humanos tiveram já vidas muito mais incertas; ao deixarem a condição símia para se tornarem hominídeos, depois humanos, partilhavam as incertezas de qualquer animal, vivendo a vida apertada e imprevisível da relação duríssima entre predador e presa. Mas a evolução nos dotou de soluções ad hoc inúmeras, como, por exemplo, a capacidade de ter medo, porquanto o animal que não teme, morre antes. Dotou-nos de atalhos automatizados para reagirmos a riscos graves e iminentes, quando não temos chance de pensar com calma, calcular os riscos e saídas mais racionais, recorrer a apoios etc. Como especificou Kahneman (2011), temos um tipo rápido de pensamento, outro lento (grosso modo). O lento é similar ao científico, ponderado, mensurado, insistentemente testado, sempre renovado etc.; o rápido são atalhos automatizados que seguimos na vida sem pensar diretamente na questão; em geral são saídas inconscientes, como achar alguma solução diante de um tigre que está para saltar em cima de nós. Temos um rol de reações automatizadas ao risco, perigo, susto, nem sempre muito acertadas, que significam a acumulação de uma "sabedoria" ou "bom senso" que nos guiam na vida incerta.

\section{ARTIFÍCIOS DA TEORIZAÇÃO}

Piaget, em sua notória teoria da equilibração, descreve como crianças pequenas forjam um "esquema" mental para nele enfiar a realidade que manipulam cotidianamente como resposta a seus porquês, representando isso uma das necessidades fundamentais da existência. Sentimo-nos forçados a buscar alguma explicação para aquilo que não entendemos e imaginamos que entender algum processo é ordená-lo linearmente. Foucault captou esse movimento em seu irônico " $A$ ordem do discurso" (2000): a ordem está no discurso, não na realidade. É artifício mental, para dar conta da realidade; de certa forma, precisamos aprisioná-la num esquema mental, para nela podermos intervir. Acrescenta Piaget, contudo, que, como a realidade nunca cabe em qualquer esquema mental, a criança acaba descobrindo que precisa superar o esquema em uso, para montar outro. Aprendizagem, para ele, está nesta transição autoral da criança: na desconstrução e reconstrução, embora o termo que veio a consagrar-se fosse da "construção" (construtivismo). A criança reconquista o "equilíbrio" mental, mas nunca em definitivo - a desconstrução/reconstrução mental da realidade persiste como aprendizagem permanente. "Teorizar", que em ciência é função nobre, ao lado de experimentar, mensurar, testar, é atividade comum mental: significa o esforço constante de padronizar dinâmicas que enfrentamos ou vivenciamos, para podermos ter algum controle delas. Uma dessas experiências mais marcantes é como crianças recém-nascidas buscam avidamente ler o rosto da mãe, padronizando suas expressões (LoBue, 2016. Dewar, 2018). Pode ser estranho falar de "teorizar", 
mas se aceitamos minimamente a noção de "esquema mental" de Piaget, a criança detém alguma habilidade inata de teorização e que vai aperfeiçoando com a experiência e convivência. Parece fundamental para a criança reconhecer como é a expressão facial da mãe, porque depreende se está de bom humor, receptiva, calorosa ou chateada.

Crianças são dadas a perguntar tudo ou quase, uma atividade que muitos valorizam extremamente, razão pela qual sugerem começar educação científica no pré-escolar (Linn \& Eylon, 2011). Não faltam educadores que reconhecem a inabilidade da escola de manter esta motivação infantil tão fundamental, apagando no ensino fundamental a volúpia de perguntar, duvidar, experimentar (Pacheco, 2017; 2019). Este tipo de atividade mental implica natural "teorização", ancorada em hipóteses de trabalho sobre como a realidade funciona, como achar uma resposta para uma pergunta difícil, como experimentar a realidade para verificar algum resultado. É claro que a teorização dita científica tem outro formato, mais rebuscado, tipicamente lógico-experimental, reconstrutivo profissionalmente. Mas a estruturação é similar, no sentido de ser um gesto mental de ordenamento da realidade, antecipando uma explicação possível. Toda teoria condensa redutivamente os traços mais básicos de um fenômeno que se pretende explicar, dentro da expectativa de que só entendemos o que ordenamos, medimos, testamos. Este "entender" é aquele científico, porque podemos encontrar outros matizes do entendimento, por exemplo, como a religião entende indícios da existência de Deus (design inteligente, digamos). A mãe entende o filho sem precisar teorizações rebuscadas como a científica, mais pelo insight materno, convivência constante, reciprocidade de comportamento etc. Assim, fabricamos teorias para antecipar uma explicação possível que vai ser intersubjetivamente testada, confirmada ou rejeitada, total ou parcialmente. O início do processo pode ser mais empírico, talvez como Darwin que colheu antes um monte de evidências empíricas, embora se tenha de reconhecer que a coleta dessas evidências se ancorava em teorização prévia imprescindível. Algumas teorizações ficaram famosas, como as Einstein, que se via cavalgando a luz correndo no espaço, desviando de obstáculos, não em linha reta. Na prática os processos se misturam, porque são imbricados naturalmente.

Teorizar pode ser um vício (teoricismo), comum em ciências sociais e humanidades, mas vigente também em ciências naturais, quando o teórico fica distante demais da realidade empírica quantitativa. Mas, de si, é procedimento fundamental da capacidade de explicar a realidade, modelando redutivamente um discurso sobre ela de cunho lógico-experimental. Começa com um "chute", uma "hipótese" que ensaia uma explicação provisória do fenômeno, reduzido a traços infraestruturais invariantes, no contexto de um processo assíduo de padronização das dinâmicas. Segue arrumando a hipótese para ajustar-se à realidade a ser explicada e conclui-se com testes da evidência empírica. Teorização e teste empírico intersubjetivo são duas faces da mesma moeda, mesmo que alguns cientistas sejam mais propensos à teoria (Einstein, por exemplo) e outros mais à empiria. O que chama a atenção na teorização é como antecipamos uma resposta provisória, por definição aberta, mas na qual estamos apostando, até prova em contrário. Esta hipótese de trabalho tenta captar, ou indicar, alguma estruturação recorrente do fenômeno, em torno da qual gira. Retornando ao exemplo marxista, a infraestrutura econômica foi a hipótese básica de trabalho que Marx lançou para explicar a sociedade, secundarizando, consequentemente, outros aspectos. Disse, então, claramente que não se analisa uma sociedade por suas ideologias, por exemplo, seus traços culturais e sociais, mas pelo sistema produtivo adotado. Esta hipótese até hoje mantém muita força, não só entre marxistas, mas também entre oponentes, que, não obstante, consideram que o substrato mais explicativo de uma sociedade está em seu sistema produtivo e vemos isso escancarado em como 
se entendem os governos nacionais atuais: seu foco é o crescimento econômico, em torno do qual tudo gira. Há muitos ministérios, mas nenhum é tão estratégico quanto os econômicos.

Esta noção de infraestrutura materialista esconde, naturalmente, pressupostos teóricos dos quais partimos. Marx achava que a realidade social era determinada materialmente (modo de produção no materialismo histórico), do que seguia que outras dimensões, não sendo acessórias, seriam dependentes. Este determinismo é obsoleto, representando uma fase "positivista" de Marx. Deixando o determinismo de lado, outros autores montam outras hipóteses, conforme a discussão vai evoluindo. Alguns autores, por exemplo, tentam conceber "informação" como bloco mais fundamental de construção do universo (Davies \& Gregersen, 2011), de alguma forma combinando com teorias físicas clássicas e quânticas, mais voltada para como a realidade é comunicativamente estruturada. Outros mantém a pretensão mais rigorosa de teorias "certas" (por conta de seus formalismos, basicamente), enquanto alguns declaram o "fim das certezas" (Prigogine, 1996. Prigogine \& Stengers, 1997. Klir, 2006). Há também quem critique a fantasia fértil de cientistas que não só reconstroem mentalmente a realidade, como a "inventam" (Penrose, 2016). Outros focam fatos científicos provocativos, como faz Panek (2011), ao alegar que só sabemos "4\% do universo" - é feito, em 96\%, de matéria negra, que ainda não deslindamos.

Por trás da teorização está uma dinâmica epistemológica sui generis. toda pergunta, para ser posta, precisa antecipar algo da resposta; se não fosse assim, nada teria a perguntar. Assim, para explicar uma realidade, precisamos de hipóteses prévias, antecipadas, chutes - um início de explicação lançada - que vamos em seguida elaborar melhor e logo testar contra evidências empírica e similares. Teoria nunca começa do zero, porque no mundo das explicações, nenhuma é o zero; todas são resultado de teorias anteriores também, adotando, rejeitando, combinando, superando. A mente, para tentar explicar a realidade, precisa mexer com ela, ordenar, formalizar, para catar padrões recorrentes que seriam os mais explicativos. Eis aqui pressuposto ingente: o invariante é mais explicativo (e ontológico), embora tenhamos a sensação constante de que, sendo a existência um fluxo complexo de dinâmicas também desencontradas, o reducionismo padronizador mental é problema da mente, não da realidade (como diria Foucault, 2000). De certa forma, para entender uma realidade é preciso "enquadrá-la" lógico-experimentalmente, sendo uma interferência que pode ser desastrada, quando, ao invés de vermos o ordenamento mental como artifício instrumental, vemos como a realidade em si. Parece também claro que o gesto de simplificação epistemológica mental é uma intrusão por conta e risco, facilmente também deturpante, como ocorre quando enviesamos a realidade para caber na teoria, precisamente como na "ditadura do método": é real o que aí cabe! Podemos captar, ao fundo desse imbróglio, que a mente não tem condição de apanhar a realidade em toda sua complexidade; é demais para ela. Apela então para um truque que tem dado certo: seleciona padrões recorrentes, confiando que eles são essenciais (para o positivismo são os únicos essenciais) ao fenômeno. Isto não inibe dar conta das dinâmicas, mas lidamos com elas peva via negativa: ou seja, analisando o lado invariante da variação. Na contraluz.

\section{CONCLUSÃO}

É comum montarmos uma hierarquia de saberes, estando no topo, em geral, o científico. Se tivermos como critério a sofisticação teórica e metodológica, por certo o científico é mais elaborado. Mas outras formas de conhecimento podem ser sumamente importantes, mais que o científico, dependendo da preocupação em jogo. Enquanto a ciência não responde a questões como o sentido da vida, da ética, 
da religiosidade/espiritualidade, outros conhecimentos esmeram-se nisso, admitindo elaborações bem sofisticadas, embora de outro cunho. Teologias podem ser muito elaboradas, como a católica e protestante. Outros saberes são menos elaborados, como senso comum, ou linguagem popular, fofoca, mas, mesmo assim, podem ser imprescindíveis na convivência social, porque exaltam as identidades. A importância do conhecimento científico está, entre outras coisas, em como se alinhou aos interesses mais prementes da sociedade, como sistemas produtivos, tecnologias de ponta, guerra e competitividade etc. É importante, certamente, mas é uma importância bem questionável. Todos os saberes são importantes e questionáveis.

De um lado, incomodam-nos as incertezas da vida, porque nos deixam de sobressalto. Doutro, investimos enorme esforço para arrumar, ordenar, formalizar as incertezas, não porque as possamos transformar em certezas - não é viável - mas porque podemos reduzir, sob conta e risco, os graus de incerteza. Que a vida é incerta, todos sabemos de experiência: para morrer, basta estar vivo, diriam os pessimistas! Acomodamo-nos às incertezas, porque nos rodeamos de artifícios mentais que nos tranquilizam, focando nelas as recorrências; continuam incertas, mas temos a impressão de as estarmos domando.

O lado mais sibilino dessa relação tão complexa é que conhecer não elimina a ignorância; precisa dessa para se realçar. Sempre que conhecemos algo, deixamos de conhecer algo.

\section{REFERÊNCIAS}

BARROW, J.D. 1994. Teorias de Tudo - A busca da explicação final. J. Zahar Ed., Rio de Janeiro.

BELLAH, R.N. 2011. Religion in Human Evolution - From the Paleolithic to the axial age. The Belknap Press of Harvard University Press.

BIEDERMAN, F. CHRISTMAN, M., JAMES, B., MENAKER, W., TEXAS, V. 2018. The Chapo guide to revolution - A manifest against logic, facts, and Reason. Touchstone, N.Y.

BRENNAN, J. \& MAGNESS, P. 2019. Cracks in the Ivory Tower: The moral mess of higher education. Oxford U. Press.

BRYNIE, F.H. 2009. Brain Sense: The science of the senses and how we process the world around us. AMACOM, N.Y.

BUONOMANO, D. 2011. Brain Bugs: How the Brain's Flaws Shape Our Lives. W. W. Norton \& Company. N.Y.

CAPLAN, B. 2018. The case against education: Why the education system is a waste of time and money. Princeton U. Press.

COLLINS, J. \& HANSEN, M.T. 2011. Great by Choice: Uncertainty, chaos, and luck - Why some thrive despite them all. HarperBusiness, N.Y.

COSTANDI, M. 2016. Neuroplasticity. The MIT Press, Cambridge.

CRIBB, J. \& SARI, T. 2010. Open Science: Sharing Knowledge in the Global Century. Cairo Publishing, N.Y.

DAMASIO, A. 2018. The strange order of things: Life, feeling, and the making of cultures. Pantheon, N.Y. 
DAMASIO, A.R. 1996. O Erro de Descartes - Emoção, razão e o cérebro humano. Companhia das Letras, Rio de Janeiro.

DAVIES, M.R. 2007. Wiki wisdom: Lessons for educators. http://www.edweek.org/dd/articles/2007/09/12/02wiki.h01.html

DAVIES, P. \& GREGERSEN, N.H. (Eds.). 2011. Information and the nature of reality. Cambridge U. Press.

DEHAENE, S. 2009. Reading in the Brain. Viking Adult, New York.

DEMO, P. 1995. Metodologia científica em ciências sociais. Atlas, São Paulo.

DEMO, P. 2005. Éticas multiculturais - Sobre convivência humana possível. Vozes, Petrópolis.

DEMO, P. 2011. A força sem força do melhor argumento - Ensaio sobre "novas epistemologias virtuais". Ibict, Brasília.

DEMO, P. 2011a. Praticar Ciência - Metodologias do conhecimento científico. Saraiva, São Paulo.

DEWAR, G. 2018. Deciphering facial expressions for kids: can we help children read emotions? Parenting Science - https://www.parentingscience.com/facial-expressions-for-kids.html

DOIDGE, N. 2007. The Brain That Changes Itself: Stories of Personal Triumph from the Frontiers of Brain Science. Penguin, London.

FIELDS, J. 2011. Uncertainty: Turning Fear and Doubt into Fuel for Brilliance. Portfolio, N.Y.

FIRESTEIN, S. 2012. Ignorance - How it drives science. Oxford University Press, Oxford.

FOERSTER, H. \& POERKSEN, B. 2008. Wahrheit ist die Erfindung eines Lügners: Gespräche für Skeptiker. Carl-Auer-Systeme. Berlin.

FOUCAULT, M. 2000. A ordem do discurso. Loyola, São Paulo.

GILES, J. 2005. Internet encyclopaedias go head to head.http://www.nature.com/nature/journal/v438/n7070/full/438900a.html

GREGERSEN, H. 2018. Questions are the answer: A breakthrough approach to your most vexing problems at work and in life. HarperBusiness. N.Y.

GRIBBIN, J. 1998. The Search for Superstrings, Symmetry, and the Theory of Everything. Little, Brown and Company, New York.

HAACK, S. 2019. Belief in Naturalism: An epistemologist's philosophy of mind. Topics in Metaphysics. In Stelmach, J. et alii (Eds.). The Normative Mind. U. of Miami Press, p. 229-249. https://www.researchgate.net/publication/333356821_2018_Belief_in_Naturalism_An_Epistemologis t's_Philosophy_of_Mind

HAIDT, J. 2006. The Happiness Hypothesis: Finding Modern Truth in Ancient Wisdom. Basic Books, N.Y.

HAIDT, J. 2012. The Righteous Mind: Why good people are divided by politics and religion. Pantheon, N.Y.

HARARI, Y.N. 2015. Sapiens: A brief history of humankind. Harper, London.

HARARI, Y.N. 2017. Homo Deus - A brief history of tomorrow. Harper, London.

HARARI, Y.N. 2018. 21 Lessons for the $21^{\text {st }}$ century. Spiegel and Grau, N.Y. 
HAWKING, S.W. 2006. The Theory of Everything: The origin and fate of the universe. Phoenix Books, Beverly Hills.

HECHT, Jennifer M. 2003. Doubt - A History - The great doubters, their legacy of innovation form Socrates and Jesus to Thomas Jefferson and Emily Dickinson. HarperSanFrancisco, New York.

HERCULANO-HOUZEL, S. 2016. The human Advantage: A new understanding of how our brain became remarkable. The MIT Press, Cambridge.

HOOKS, B. 2009. Teaching Critical Thinking: Practical wisdom. T \& F Books, London.

HORGAN, J. 1997. The End of Science - Facing the limits of knowledge in the twilight of the scientific age. Broadway Books, New York.

HORGAN, J. 2002. A Mente Desconhecida - Por que a ciência não consegue replicar, medicar e explicar o cérebro humano. Companhia das Letras, São Paulo.

IOSCHPE, G. 2004. A Ignorância Custa um Mundo - O valor da educação no desenvolvimento do Brasil. Francis, São Paulo.

KAHNEMAN, D. 2011. Thinking, Fast and Slow. Penguin, N.Y.

KAUFFMAN. S.A. 2019. A world beyond physics: The emergence and evolution of life. Oxford U. Press.

KEKES, J. 1995. Moral Wisdom and Good Lives. Cornell University Press, Ithaca.

KITTUR, A., CHI, E., PENDLETON, B.A., SUH, B., MYTKOWICZ, T. 2007. Power of the Few vs. Wisdom of the crowd: Wikipedia and the rise of the bourgeoisie. http://www.viktoria.se/altchi/submissions/submission_edchi_1.pdf

KLIR, G.J. 2006. Uncertainty and Information: Foundations of generalized information theory. Willey, New York.

LENTS, N. 2018. Human Errors: A panorama of our glitches, from pointless bones to broken genes. Weidenfeld \& Nicolson, N.Y.

LIH, A. 2009. The Wikipedia Revolution. Hyperion, New York.

LINN, M.C. \& EYLON. B.-S. 2011. Science Learning and Instruction - Taking advantage of technology to promote knowledge integration. Routledge, N.Y.

LOBUE, V. 2016. Face time: here's how infants learn from facial expressions. The Conversation http://theconversation.com/face-time-heres-how-infants-learn-from-facial-expressions-53327

MARCH, J.B. 2011. The ambiguities of experience. Kindle Edition, N.Y.

MCGRAYNE, S.B. 2011. The Theory That Would Not Die: How Bayes' Rule Cracked the Enigma Code, Hunted Down Russian Submarines, and Emerged Triumphant from Two Centuries of Controversy. Yale University Press, Yale.

NIELSEN, M. 2012. Reinventing Discovery: The New Era of Networked Science. Princeton University Press, Princeton.

PACHECO, J. 2017. Reconfigurando a escola - Transformar a educação. Cortez, São Paulo.

PACHECO, J. 2019. Inovar é assumir um compromisso ético com a educação https://mail.google.com/mail/u/0/\#inbox/KtbxLrjNcfBChBxsgpmHXhZzHrrcrFTkIB?projector=1\&mess agePartId $=0.1$ 
PANEK, R. 2011. The 4 percent universe: Dark matter, dark energy, and the race to discover the rest of reality. Mariner Books, Wilmington.

PEARL, J. \& MACKENZIE, D. 2018. The book of why: The new science of cause and effect. Basic Books, N.Y.

PENROSE, R. 2016. Fashion, Faith, and fantasy in the new physics of the universe. Princeton U. Press, Princeton.

PIAGET, J. 1990. La Construction du Réel chez l'Enfant. Delachaux \& Niestlé, Paris.

POERKSEN, B. 2004. The Certainty of Uncertainty - Dialogues introducing constructivism. Imprint Academic, London.

PRENSKY, M. 2008. Homo Sapiens Digital: Technology is their birthright. http://innovateonline.info/pdf/vol5_issue3/H._Sapiens_Digital-

_From_Digital_Immigrants_and_Digital_Natives_to_Digital_Wisdom.pdf

PRENSKY, M. 2012. From Digital Natives to Digital Wisdom - Hopeful essays for $21^{\text {st }}$ century learning. Corwin, Thousand Oaks.

PRIGOGINE, I. 1996. O Fim das Certezas - Tempo, caos e as leis da natureza. Ed. UNESP, São Paulo. PRIGOGINE, I./STENGERS, I. 1997. A Nova Aliança. Ed. UnB, Brasília.

RAMACHANDRAN, V.S. 2012. The Tell-Tale Brain: Unlocking the mystery of human nature. Cornerstone Digital, N.Y.

RAMIREZ, A. 2013. Save Our Science: How to Inspire a New Generation of Scientists. TED Conferences, N.Y.

ROTHMAN, T. \& SUDARSHAM, G. 1998. Doubt and Certainty - The celebrated academy. Perseus Books, Reading, Massachusetts.

SALOMON, D.V. 2000. A Maravilhosa Incerteza - Pensar, pesquisar e criar. Martins Fontes, São Paulo.

SANTOS, B.S. (Org.). 2009. As Vozes do Mundo. Civilização Brasileira, Rio de Janeiro.

SANTOS, B.S. \& MENESES, M.P. (Orgs.). 2009. Epistemologia do Sul. Almeida, Portugal.

SLOTTA, J.D. \& LINN, M.C. 2009. Wise Science - Web-based inquiry in the classroom. Teachers College Press, N.Y.

STERNBERG, R.J. (Ed.). 1990. Wisdom - Its nature, origins, and development. Cambridge University Press, Cambridge.

SURI, G. \& BAL, H.S. 2010. A certain ambiguity: A mathematical novel. Princeton U. Press, N. Jersey.

SUROWIECKI, J. 2004. The Wisdom of Crowds: Why the many are smarter than the few and how collective wisdom shapes business, economics, societies, and nations. Doubleday, New York.

WALES, $\quad 2006 . \quad$ T. The Wisdom of http://www.guardian.co.uk/commentisfree/2008/jun/22/wikipedia.internet

WATTS, A.W. 1951. The Wisdom of Insecurity - A message for an age of anxiety. Vintage Books, N. York.

WEINBERG. S. 2020. "The more comprehensible the universe becomes the more pointless it seems" - https://www.azquotes.com/quote/957863. 